\title{
The Role of Psychic Distance in Entry Mode Decisions: Magnifying the Threat of Opportunism or Increasing the Need for Local Knowledge?
}

\author{
Douglas Dow \\ Professor in Business Strategy, Melbourne Business School, The University of Melbourne, \\ 200 Leicester Street, Carlton, Victoria, 3053 AUSTRALIA; Phone: ++ 61393498149 \\ Email: d.dow@mbs.edu
}

\begin{abstract}
Daniel Baack
Associate Professor of Marketing, Daniels College of Business, University of Denver, 2101 S. University Blvd., Denver, CO 80208-8921 USA; Phone: ++ 13038713817

Email: Daniel.Baack@du.edu
\end{abstract}

\section{Ronaldo Parente}

Knight Ridder Fellow Associate Professor of Strategy \& International Business

Florida International University \& FGV-EBAPE

11200 SW 8th Street - MANGO 437 | Miami, FL 33199

O: $++1305.348 .4566 \quad$ C: ++1.410 .4307962$

Email: reparent@,fiu.edu

This is the author manuscript accepted for publication and has undergone full peer review but has not been through the copyediting, typesetting, pagination and proofreading process, which may lead to differences between this version and the Version of Record. Please cite this article as doi: 10.1002/gsj.1309

This article is protected by copyright. All rights reserved. 
Running Head: The Role of Psychic Distance

Keywords: $\quad$ Entry Mode, Psychic Distance, New Internalization Theory, Transaction Cost Theory, Experiment

This article is protected by copyright. All rights reserved. 


\begin{abstract}
Research Summary

With respect to entry mode decisions, psychic distance may play two contradictory roles. On one hand, the Transaction Cost perspective is concerned with opportunism. Psychic distance magnifies the threat of opportunism, which encourages higher levels of control by foreign firms. Conversely, the New Internalization perspective emphasizes the role of complementary assets controlled by local entities. Distance increases the need to access local knowledge; which encourages firms to seek joint ventures. By adopting an experimental approach, and measuring managers' a priori perceptions of distance, this paper contributes to the literature by providing a more sophisticated approach for discriminating between these effects. The results indicate that distance magnifies the need for firms to access complementary assets; however, distance does not appear to magnify the threat of opportunism.
\end{abstract}

\title{
Managerial Summary
}

This paper explores the role that psychic distance (i.e. differences across countries in culture, language, religion, etc.) plays in how firms enter foreign markets. Specifically, do they prefer wholly-owned subsidiaries (WOS), or do they prefer to form joint ventures (JV) with local players? One perspective argues that firms are concerned about potential partners in a foreign market taking advantage of them; thus, they will prefer the greater control that a WOS offers. Conversely, firms may simply recognise that these differences put them at a disadvantage, and 
they prefer a JV as a way to gain local knowledge. Our experiments indicate that the latter explanation dominates. When entering very different countries, managers seem to prefer JVs in order to access key local knowledge. 


\section{The Role of Psychic Distance in Entry Mode Decisions: Magnifying the Threat of Opportunism or Increasing the Need for Local Knowledge?}

\section{INTRODUCTION}

The choice of foreign operation modes is a complex issue. Not only is there a broad range of possible alternatives (e.g. exporting, licencing, non-equity alliances, wholly-owned subsidiaries, joint ventures, greenfield investments and acquisitions), but firms often use multiple modes at any given time, and these modes typically evolve over time (Benito, Petersen and Welch, 2009). Whenever a firm makes such choices, the process may typically involve a substantial capital investment, will certainly necessitate a great deal of senior management time and effort, and will be relatively hard to reverse. As a result, such decisions have attracted a substantial amount of investigation in the international business (IB) literature.

This paper focuses on a particular aspect of one such decision: how various forms of cross-national differences or distances ${ }^{1}$ influence entry mode choices - i.e. the choice of whether a foreign subsidiary should be a wholly-owned subsidiary (WOS) or an equity joint venture (EJV) with a local partner. This specific issue is arguably one of the most heavily investigated aspects of foreign operation modes (Shaver, 2013). Indeed, there are at least four published meta-analyses on the issue (Magnusson et al., 2008; Morschett, Schramm-Klein, and Swoboda, 2010; Tihanyi, Griffith, and Russell, 2005; Zhao et al., 2004); and yet, the empirical results concerning the distance-entry mode relationship are at best equivocal and inconsistent. The four aforementioned meta-analyses have analysed 36, 72, 38 and 55

\footnotetext{
${ }^{1}$ For the purposes of this paper, the term distance does not refer to geographic distance (i.e. miles or kilometres) but rather to a broad set of differences between countries that are variously referred to as cultural distance, psychic distance, socio-cultural distance, or institutional distance.
} 
independent samples respectively, and found at most 'only a small main effect' (Magnusson et al., 2008).

We argue that these equivocal results may be due to a combination of theoretical and methodological issues. At the theoretical level, one difficulty is that large distances between markets may play two counter-opposing roles in an entry mode decision (Brouthers and Brouthers, 2001; Slangen and van Tulder, 2009). On one hand, what we will refer to as the classic Transaction Cost perspective argues that multinational enterprises (MNE) will tend to enter distant markets via WOS. This perspective builds directly on Williamson's (1975) transaction cost economics (TCE) thesis, and was first applied to the international entry mode decision by Anderson and Gatignon (1986). It predicts that the ambiguity and communication difficulties brought about by large distances between markets, combine with high asset specificity and information asymmetry ${ }^{2}$, making it difficult for parent firms to monitor and control local partners; thus exposing them to opportunistic behaviour (e.g. Zhao, Luo and Suh, 2004). Anderson and Gatignon (1986) refer to this as internal uncertainty. In response to this form of uncertainty, it is predicted that firms may prefer higher control modes (i.e. wholly-owned subsidiaries) in order to reduce the risk of opportunism.

Nevertheless, there is also another possible interpretation of the role of distance in entry mode decisions. As most forcefully argued by Hennart $(1988,2009)$, the issue of whether a local joint venture is formed, as opposed to an MNE entering a foreign market via a WOS, actually requires two forms of market failure - the failure of the market for the MNE's firm-specific-assets and the failure of the market for critical country-specific-assets. A joint venture should only eventuate when both failures occur. This perspective is referred to as New Internalization theory by Verbeke and Kano (2015). The role that distance plays

\footnotetext{
2 A great deal of the transaction cost literature (e.g. Zhao, et al. 2004) uses the term asset specificity in such instances; however, Brouthers and Hennart (2007) note that the concept of information asymmetry provides a more convincing argument. For brevity we shall use the term asset specificity but acknowledge the ongoing debate on this issue.
} 
here is in creating an information asymmetry (Cuypers, Ertug and Hennart, 2015); and thus, magnifying the need for MNEs to access complementary local knowledge through joint venture partners to compensate for that additional disadvantage. The ambiguity and communication difficulties brought about by large distances between markets make it difficult for managers from foreign countries to understand, predict and manage what might eventuate in a local market. Anderson and Gatignon (1986) refer to this as external uncertainty. As a result of this uncertainty, it is predicted that MNEs will seek out 'complementary assets controlled by host-market ... actors' (Verbeke and Kano, 2015: 421); and thus, will prefer joint ventures with local firms over wholly-owned subsidiaries in order to access the necessary local market-specific knowledge and reduce their risk (e.g. Hennart and Larimo, 1998).

Unless researchers explicitly acknowledge these two competing effects of distance, and devise strategies to discriminate between them, one is never certain if a weak or nonsignificant result, such as found by several of the meta-analyses, indicates that both effects are weak or non-significant, or whether they are both substantive but simply cancelling each other out. Unfortunately, only a relatively small number of articles (e.g. Brouthers and Hennart, 2007; Slangen and van Tulder, 2009) have even acknowledged this conflict, and only three to our knowledge have empirically explored this dilemma in any form (Agarwal, 1994; Brouthers and Brouthers, 2001; Erramilli and Rao, 1993).

A second factor that may be contributing to the equivocal results concerning the distanceentry mode relationship is methodological in nature. It is undeniable that the majority of the existing entry mode research relies heavily on large-scale surveys of firms and secondary data. This is a major concern given that many of the aforementioned constructs, such as cross-national differences/distances, perceptions of risk, and asset specificity, are abstract in nature and difficult to measure. Indeed, while we applaud the pioneering efforts of Erramilli 
and Rao (1993), Agarwal (1994), and Brouthers and Brouthers (2001), the empirical portions of their investigations still rely on crude indicators of their main constructs. For example, all three papers employ the national-level Hofstede-based (1980) cultural distance dimensions. This metric in particular has been increasingly criticised (Tung and Verbeke, 2010; Zaheer, Schomaker, and Nachum, 2012); and indeed Zhao et al. (2004) has demonstrated that secondary-source measures of cultural distance such as this, yield significantly smaller effect sizes than perceptual approaches. In addition to that, both Agarwal (1994) and Erramilli and Rao (1993) rely on a very crude moderator to control for instances where the threat of opportunism is likely to be higher - specifically they use R\&D intensity as a measure of asset specificity. ${ }^{3}$ Thus the ambiguous results may also be due to inadequacies of how the key constructs have been measured in the past (Brouthers and Brouthers, 2001; Zhao et al., 2004).

We resolve this issue not by putting forth another large-scale field survey, but rather by embracing the calls of Buckley, Devinney, and Louviere (2007) and Leung, Bhagat, Buchan, Erez, and Gibson (2005) and employing an experimental approach to investigate the relationship. We strongly believe that an experimental design offers several advantages. First, it allows more refined and subtle measurement of abstract constructs, rather than relying on crude proxy variables (such as the Hofstede-based cultural dimensions); second, the experimental approach is particularly effective at investigating moderating relationships (Leung et al., 2005); third, in contrast to field studies, our approach allows one to more effectively control other factors; and fourth, it is superior over other techniques in demonstrating causality (Leung et al., 2005).

In brief summary, our research objective is to explore the role that distance plays in entry mode decisions through the use of individual-level experiments utilising actual managers,

\footnotetext{
3 The third study by Brouthers and Brouthers (2001) does not measure asset specificity but rather uses market risk as their moderator of distance.
} 
rather than through secondary source data or a large-scale survey of firms. As a result, we believe this paper contributes to the literature in three specific ways. At the theoretical level, it is one of the few papers to explicitly acknowledge the contradictory roles of distance (i.e. magnifying the threat of opportunism or magnifying the need to access local complementary assets); and along with Erramilli and Rao (1993), Agarwal (1994), and Brouthers and Brouthers (2001), it is one of only three efforts to our knowledge to develop and implement an approach for discriminating between these counter opposing roles. Second, while addressing this issue, we bring to the empirical entry mode literature a methodological approach — experimental design—which 'is sorely underrepresented in IB research' (Leung et al., 2005: 370), and is particularly suited to investigating the issues at hand. This allows us to better clarify the role that distance actually plays in the entry mode decision. Third, again as a direct benefit of our experimental approach, we are able to test and confirm superior approaches to measuring three key but complex constructs in the entry mode decision process: perceptions of psychic distance, perceptions of risk, and the threat of opportunism. In particular, along with the affiliated article ${ }^{4}$, this is the first entry mode study that we are aware of which uses a priori perceptions of distance, rather than crude secondary indicators of distance (e.g. Kogut and Singh, 1988).

The next section of this paper briefly reviews the existing entry mode literature, lays out the two main theoretical perspectives on the distance-entry mode relationship, and concludes with three hypotheses. The third section of the paper then presents the details of the research methodology, the fourth section summarizes the results, and the final section discusses the implications of the results and draws conclusions.

\footnotetext{
${ }^{4}$ This article and Baack, Dow, Parente and Bacon (2015) are part of a common research project and share a common survey and sample population.
} 


\section{LITERATURE REVIEW, THEORETICAL FOUNDATIONS AND HYPOTHESES}

Before embarking on a detailed discussion of the role of distance in entry mode choices, it is critical that we define one of the more ambiguous constructs in this debate - the concept of distance. For the purposes of this paper, we employ the concept of psychic distance as defined by Johanson and Vahlne (1977: 24) - 'the sum of factors preventing the flow of information from and to the market. Examples are differences in language, education, business practices, culture, and industrial development.' As will become evident in the subsequent discussions, we feel that this is an appropriate definition of distance as it explicitly captures the underlying issues at hand - the fact that distance frequently handicaps managers in foreign markets in terms of their ability (or inability) to effectively understand and communicate with various stakeholders in that market. Nevertheless, at various points in our review of the literature, we will also use the more generic term distance to reflect the fact that a variety of terms such as cultural distance, socio-cultural distance, institutional distance, and psychic distance heavily overlap one another, and are frequently used within the same theoretical context.

We also note that a number of concerns have been expressed in the IB literature concerning how the concept of distance is conceived and implemented (Shenkar, 2001; Håkanson and Ambos, 2010; Tung and Verbeke, 2010; Håkanson, Ambos, Schuster and Leicht-Deobald, 2016). For those reasons, throughout the paper we use perceptions of psychic distance at the individual level, rather than national level psychic distance stimuli (Dow and Karunaratna, 2006). This approach resolves concerns about assumptions of stability over time, asymmetry, and within country diversity. 


\section{Psychic distance and entry mode - the need for tacit local knowledge}

As mentioned in the introduction, one role that distance might play in entry mode choice is what we refer to as the new internalization perspective (Verbeke and Kano, 2012; Verbeke and Kano, 2015); although the same underlying idea has been touched on or acknowledged by a wide range of scholars (e.g. Delios and Beamish, 1999; Brouthers and Brouthers, 2001; Meyer, 2001; Benito, Petersen and Welch, 2011). The foundation of this perspective is the view that firms from psychically distant markets are viewed as lacking in a critical form of tacit knowledge about the local environment - i.e. the knowledge of how to effectively understand, communicate with, and negotiate with various stakeholders in the local market be they local employees, union officials, customers, competitors, suppliers, or government bodies. This may result in a variety of disadvantages for the foreign firm, such as lost productivity (e.g. greater risk of industrial action or strikes), absenteeism and slack, greater customer dissatisfaction due to misinterpretation of customer needs and concerns, and/or greater regulatory delays and misunderstandings due to ineffective management of relationships with regulatory bodies. These communication difficulties may also hamper the firm's ability to predict future events in the marketplace.

From a new internalization perspective, this disadvantage due to distance increases the need for particular tacit country-specific assets (CSAs). However we are not talking about here just a set of skills or knowledge specific to the host country; but rather, such skills or knowledge that are difficult to codify, value, and implement. For that reason, we draw upon Hennart's (1988) definition of tacit knowledge as 'knowledge [which] cannot be embodied in designs, specifications, and drawings, but instead is embedded in the individual possessing it. When knowledge is tacit, it cannot be effectively transferred in codified form.' This is knowledge that is difficult to acquire in an arms-length transaction. Simply purchasing a book 
or reading a manual on how to understand and interact with people from a foreign culture is not sufficient.

One possible response to the need for tacit knowledge is to simply hire a person who embodies this knowledge; however, these skills and knowledge need to be integrated into the firm. For example, if an American firm is in the oil industry and wants to operate in Vietnam, it does not just need to hire a translator or an employee who can speak Vietnamese and understand the local market, it needs to hire a petroleum engineer who can speak Vietnamese and understand the local market. There needs to be an integration of the local market knowledge and industry-specific knowledge. Moreover, the firm does not just need one such person, it typically will need hundreds of such skilled individuals, be they engineers, technicians, sales representatives, foremen, or senior managers. While the need for this combination of skills already narrows the pool of potential employees, the situation is made worse by the fact that such individuals will tend to be concentrated in particular areas specifically in the employment of local competitors or complementary firms in the same industry. Hiring such a large number of particularly skilled individuals away from existing local firms is often not feasible. It is this combination of these factors that increases the likelihood of market failure in terms of the foreign firm sourcing these skills and knowledge. Hennart (2009) identifies such a market failure in acquiring a critical CSA as the key issue in discriminating between whether an MNE should enter into a foreign market via an EJV or a WOS.

Now we should note here two related issues. First, the other key criterion in order to justify the existence of an international EJV is for the MNE to hold a firm-specific asset (FSA) which is also difficult to transact (Hennart, 2009). The presence of such a FSA is an underlying assumption of this paper, and is specifically embedded in our experimental approach as a technology-based knowledge asset held by the foreign MNE. The second issue 
is that we want to acknowledge that other CSAs may exist that are not related to distance.

We are merely arguing here that as the distance between a host market and the MNE's home market increases, the likelihood and importance of such a local knowledge-related CSA will increase.

As a result, this theoretical perspective predicts that large psychic distances will be associated with a preference for equity joint ventures (over wholly-owned subsidiaries) in order to access the local knowledge; and a preference for lower levels of equity participation by the foreign MNE within such equity joint ventures, in order to motivate the EJV partners (Cuypers et al., 2015).

\section{Psychic distance and entry mode - the threat of opportunism}

Notwithstanding the preceding discussion, an equally valid application of TCE to the distance-entry mode relationship involves the interpretation of psychic distance as a source of internal uncertainty; thus increasing the threat of opportunism by possible joint venture partners. Anderson and Gatignon (1986: 7) define internal uncertainty as 'the entrant's inability to determine its agents' performances' and, as a result, the entrant is unable to guard itself against various forms of opportunism by the local agent, or in our specific context a joint venture partner. This may arise in the form of shirking and free-riding by the joint venture partner, where they systematically under-invest in the local market while enjoying the benefits of the other partner's firm-specific advantages (Hennart and Zeng, 2005). Alternatively, once a local partner has mastered the tacit knowledge that was brought to the joint venture by the foreign parent, the local partner may attempt to dissolve the joint venture and use the tacit knowledge exclusively for their own purposes (Hennart and Zeng, 2005). In both instances, high internal uncertainty inhibits the foreign parent's ability to identify and monitor such behaviours; and thus, take corrective action. 
In empirical research, internal uncertainty is most commonly measured in terms of a firm's degree of international experience (Brouthers and Hennart, 2007). However, as already noted, cultural distance is also often cited as a source of internal uncertainty (e.g. Malhotra, Sivakumar, Zhu, 2011; Slangen and van Tulder, 2009; Zhao et al., 2004). The underlying argument with respect to international experience is that as a firm operates in the local market, it becomes more competent at understanding, monitoring, and assessing the behaviour and performance of local joint venture partners. Thus, as international experience increases, internal uncertainty decreases. With respect to psychic distance, the link with internal uncertainty is a direct positive relationship. Differences in language, religion, culture, education systems, and business practices make it difficult for the foreign manager to correctly diagnose the underlying causes of poor performance and to detect opportunistic behaviours by its joint venture partner. As a result, as the psychic distance of a market increases, the internal uncertainty increases, and in turn the threat of opportunism increases.

The classic TCE prescription in the face of potential opportunism and market imperfections is for the firm to seek greater control (e.g. Williamson, 1979; Gatignon and Anderson, 1988; Brouthers and Hennart, 2007). As a result, the distance-entry mode prediction from the classic transaction cost perspective (e.g. Chang and Rosenzweig, 2001; Erramilli and Rao, 1993; Padmanabhan and Cho, 1996) is that in circumstances of high internal uncertainty (such as generated by large distances), a firm will seek higher levels of control (e.g. full ownership or at least higher levels of equity). Thus, with the opportunismbased explanation, as compared to the accessing local assets-based explanation, the direction of the relationship between distances and entry mode is reversed.

One key difference between these two competing explanations is that in one, curbing opportunism is the primary motivating concern, whereas in the other accessing local complementary assets is the main concern. Psychic distance is relevant to the former because 
a large psychic distance between the MNE and the host market can hinder the firm's ability to understand, monitor, and assess the behaviour and performance of the local EJV partner. Conversely, a large psychic distance between the MNE and its local stakeholders such as employees, customers, competitors, and regulatory bodies limits the firm's ability to understand, manage and predict future events in the market place. Thus, psychic distance can be argued to be a source of both forms of uncertainty.

\section{Distance and entry mode - the empirical evidence}

The relationship between distance and entry mode, regardless of the predicted direction, has been empirically tested in more than 72 distinct settings (Morschett et al., 2010) and, as already noted, the overall results have been re-analysed in at least four separate metaanalyses. At face value, the results of these meta-analyses are reasonable consistent. While both Zhao et al. (2004) and Magnusson et al. (2008) found small but significant effects supporting the external uncertainty prediction (i.e. a positive correlation between distance and the use of joint ventures); Tihanyi et al. (2005) and Morschett et al. (2010) both found no evidence of a systematic direct effect. Indeed, even Magnusson et al. (2008: 524) concludes with a caveat on their findings that 'with a cumulative sample size exceeding 30,000, virtually any correlation will be statistically significant.'

These weak results have frequently been blamed on measurement issues (e.g. Child, Ng, and Wong, 2002) since the vast majority of studies have operationalized distance solely in terms of a formative index based on Hofstede's (1980) culture dimensions (Zhao et al., 2004; Slangen and Van Tulder, 2009). As elucidated by Shenkar (2001), and more recently by others (Dow and Larimo, 2009; Tung and Verbeke, 2010; Ambos and Håkanson, 2014), not only are Hofstede's measures of cultural distance excessively narrow, but there are strong arguments that such constructs should be measured in terms of the perceptions of the 
individual rather than in terms of national-level secondary indicators. It is our contention that this excessive reliance on secondary indicators is a direct result of the dominant methodological approach. To our knowledge, essentially all empirical research on the issue of entry mode choice has used post-hoc large sample-size field surveys. Indeed, the average sample size across the 66 studies reviewed by Tihanyi et al. (2005) was 365 investments. We believe that this bias towards such samples and the criticisms mentioned above (i.e. a heavy reliance on national-level secondary indicators) are not coincidental. We raise this issue as it has major implications for our ultimate choice of research methodology. If one is going to move to more complex measurement instruments, a shift to an experimental methodology is to some extent unavoidable.

A second issue that may be confounding the empirical results is the directly opposing predictions discussed in the preceding sections. While a few authors, such as Zhao et al. (2004), Brouthers and Hennart (2007), and Slangen and van Tulder (2009), have acknowledged this conflict, to our knowledge, only the three studies mentioned previously (Agarwal, 1994; Brouthers and Brouthers, 2001; Erramilli and Rao, 1993) have explicitly attempted to discriminate between the directly opposing predictions with respect to the distance-entry mode choice relationship. Effectively controlling for these opposing effects is a concern because a non-significant empirical result could still imply one of two possibilities. It may imply that both predictions concerning distance and entry mode are not supported; however, it may also imply that the two opposing effects are significant but of sufficiently equal strength to nullify each other. For that reason, the next section outlines our approach for discriminating between these two potential effects, thus resolving this dilemma. 


\section{Discriminating between the two effects}

\section{The moderating role of the threat of opportunism}

The key issue in distinguishing between the counter-opposing roles of distance in entry mode choice is the moderating role of what we term the threat of opportunism. People familiar with the TCE tradition will associate this with asset-specificity. However, we argue that the threat of opportunism needs to be a broader concept which more directly captures what we see as the key issue: to what extent do particular aspects of the scenario, such as attributes of the firm, product or technology, create greater or lesser threat of opportunism on the part of a firm's local partners? Asset-specificity is certainly a contributing factor to the threat of opportunism, but we believe there are other aspects as well.

In the TCE tradition, particularly as applied to foreign entry mode choices (e.g. Anderson and Gatignon, 1986; Gatignon and Anderson, 1988; Hennart, 1988; Hennart, 1991), asset specificity or transaction-specific assets are viewed as critical because they increase the threat of opportunism in the form of hold-up; and thus may create inefficient markets. One of the more common forms of transaction-specific assets arises in the market for knowledge and, as a result, in empirical studies the research intensity of a firm or industry has virtually become the de facto indicator for the threat of opportunism (Zhao et al., 2004). We argue that this approach is excessively narrow. As emphasized by Hennart (1988), some forms of knowledge are substantially more tacit than others and thus, even if minimal transaction specific adaptation is required, they may be more difficult to patent - an institution specifically introduced to reduce the problems of hold-up and opportunism. It can also be argued that some forms of knowledge are more prone to shirking and free riding. For example, if a particular technology results in lower manufacturing costs, then the benefits should be relatively evident in the accounting results and thus quickly expose any shirking. However, if the primary benefit of a technology is in the form of higher product quality, such 
as a lower failure rate or longer product life, then the detection of shirking may be more problematic, at least in the early phase of a joint venture. As a result, we argue that the threat of opportunism, while strongly related to technology intensity, is a broader concept and needs to include the ability of the firm to legally protect itself against hold-up and opportunism (e.g. patent and copyright systems) and the degree to which the benefits are easily measurable, thus limiting shirking and free-riding.

Therefore, our main argument is that the threat of opportunism positively moderates (i.e. strengthens) the role of distance as a source of internal uncertainty and its resultant impact on entry mode choice. As one can note from our preceding discussions, the key issue with respect to internal uncertainty (in this instance generated by large psychic distances) is that the foreign firm is less able to monitor the performance and behaviours of its local partners and thus less able to detect opportunistic behaviour. If the situation is such that there is a higher threat of opportunism, then the inability to monitor one's local partners becomes a more critical issue. Conversely, if the situation is such that there is a lower threat of opportunism, then the inability to monitor the local agent's behaviour becomes less critical. In one sense, this moderating relationship has a long history in the TCE literature. Brouthers and Hennart (2007: 403) note that 'for Williamson, uncertainty is only problematic when coupled with asset specificity.' Sadly, to a large extent this moderating relationship has been neglected in the empirical research. To our knowledge only Erramilli and Rao (1993), Agarwal (1994), and Brouthers and Brouthers (2001) implemented any such form of moderating relationship in their empirical analyses. In the cases of Agarwal (1994) and Erramilli and Rao (1993), they used the research intensity of the firm as their moderator while Brouthers and Brouthers (2001) used market risk. While we commend these pioneering effort, all of these would be considered weak or limited measures of the threat of opportunism. 
In contrast, we note that our preceding arguments underlying the need for tacit local knowledge perspective (i.e. large psychic distances leading to a preference for joint ventures and lower equity holdings) do not imply any such moderating relationship. Thus, it should be possible to discriminate between the perspectives by contrasting the impact of distance on mode choice across two distinct opportunism scenarios. In a low threat of opportunism scenario, the impact of distance on mode choice should primarily reflect the accessing local knowledge perspective. Whereas, in a high threat of opportunism scenario, both perspectives should be reflected; and thus, the difference between the two scenarios (i.e. the moderating effect) should reflect the classic TCE perspective.

\section{Hypotheses Development.}

At this point we formalise the predictions emerging from the preceding discussions into three sets of testable hypotheses; however, before doing so, we want to clarify one additional aspect. For each of our hypotheses, we have intentionally acknowledged the mediating role that perceptions of risk play in the process. In both perspectives, large psychic distances are expected to increase uncertainty and thus perceptions of risk, even though the managers are ultimately expected to select different entry modes in an effort to reduce that risk. As a result, each hypothesis contains two parts. The first part acknowledges the impact of the relevant predictor variable (e.g. distance) on the manager's perceptions of risk. The second part of the hypothesis reflects the impact of the predictor variable on the preferred entry mode.

Our first hypothesis reflects what we have characterised as the accessing complementary local assets perspective. This perspective predicts that large psychic distances will inhibit a foreign-owned firm's ability to understand and communicate with the various stakeholders in the local market. This will magnify their inability to understand, manage and predict future events in the market place and will therefore increase their perceptions about the risk of doing 
business in that market. In response to this, managers will prefer joint ventures and lower equity shares of joint ventures in order to access the cooperation of skilled local managers who do not suffer the same disadvantage, and to appropriately incentivise those managers. This hypothesis is arguably the most common prediction within the empirical entry mode literature and variations of it can be found in a broad range of papers spanning more than 20 years (e.g. Gatignon and Anderson, 1988; Erramilli and Rao, 1993; Agarwal, 1994; Hennart and Larimo, 1998; Brouthers and Brouthers, 2001; Dow and Larimo, 2009). Hence we propose the following hypothesis:

Hypothesis 1: As the psychic distance of a market from the foreign manager's home market increases, the foreign manager's ...

a) perception of the business risk of that host market will increase, and b) his/her preference for high levels of equity control will decrease.

Our second hypothesis does not directly concern the role of distance but rather concerns the direct impact of the threat of opportunism. Within the classic TCE perspective, the threat of opportunism is one of the countervailing factors that limit firms from defaulting to even lower commitment modes such as licensing. When there is a high potential of opportunism by the local partner, managers will perceive higher levels of business risk and, as a result, will favour higher control entry modes in order to protect them against such opportunism. This hypothesis is fundamental to any application of TCE to entry mode decisions and, as result, variations of it (usually employing research intensity as a surrogate for the threat of opportunism) can be found in a similarly broad range of papers (e.g. Brouthers, 2002; Demirbag, Glaister, and Tatoglu, 2007; Gomes-Casseres, 1990; Meyer, 2001). Hence we propose the following hypothesis: 
Hypothesis 2. In scenarios with a high threat of opportunism (i.e. difficulties in protecting the firm's proprietary assets and competitive advantages), a foreign manager's

a) perception of the business risk of that market and

b) his/her preference for high levels of equity control

... will be greater than when compared with scenarios with a low threat of opportunism.

The third and final hypothesis involves the moderating relationship between psychic distance and the threat of opportunism. In our opinion, this is the appropriate approach to testing the role of distance with respect to opportunism, and is the key to discerning whether the non-significant relationship between distance and entry mode reported by Zhao et al. (2004) and others simply represents the curbing opportunism and seeking complementary local asset effects cancelling each other out, or whether both effects are trivial in magnitude. The underlying logic is that while psychic distance may inhibit a manager's ability to effectively monitor the behaviour and performance of his/her partners in a foreign market; its actual impact on perceptions of risk and a preference for higher levels of control (to limit that risk) are contingent on the threat of opportunism. As the threat of opportunism increases, the inability to effectively monitor the agents becomes more critical, increasing the perceptions of risk and the desire for higher control to mitigate that risk. As Brouthers and Hennart (2007) argue, this moderating relationship is inherent to the traditional Williamson approach to TCE but it is rarely reflected in the empirical research. As already mentioned, only two empirical papers to our knowledge have included such a moderating relationship (Agarwal, 1994; Erramilli and Rao, 1993 - both employing research intensity as a surrogate for the 
threat of opportunism); however, neither explicitly investigates the contradictions between the perspectives ${ }^{5}$. Hence we propose the following hypothesis:

Hypothesis 3. In scenarios with a high threat of opportunism (i.e. difficulties in protecting the firm's proprietary assets and competitive advantages), there will be a stronger positive relationship between the psychic distance of a market from the foreign manager's home market, and the foreign manager's ...

a) perception of the business risk of that market and

b) his/her preference for high levels of equity control ... than in scenarios with a low threat of opportunism.

\section{METHODOLOGY}

Before progressing onto the specifics of our research methodology, we need to appropriately frame a few aspects of this research agenda. The issue of predicting whether an MNE initial enters a particular country via an EJV or a WOS is a complex multi-level issue (Benito et al., 2009). Notwithstanding our focus on the role of distance in the preceding hypotheses, we openly acknowledge that a broader range of potential factors may influence the actual mode that is adopted. Beyond the control variables commonly employed in the empirical entry mode literature, firms may also choose to enter into EJVs for completely different reasons ranging from maximizing economies of scale to responding to government regulations which mandate it, and/or to allaying xenophobia reactions (Hennart, 1988). Whether the MNE or the local partner have other businesses which the venture needs to be coordinated with, may also create goal conflicts (Hennart and Zeng, 2005). Similarly, as Hennart (2009) notes, EJVs require the agreement of two parties - a perspective seldom reflected in the empirical

\footnotetext{
${ }^{5}$ Indeed, for one of these two articles (Erramilli and Rao, 1993) the distance-research intensity relationship was only one of six moderators and the results were dropped from the analysis and only mentioned in an endnote.
} 
literature. The complementary local assets that the MNE seeks may also be unrelated to local knowledge and distance. For these reasons, we argue that studies that seek to predict actual entry mode decisions through panel data or large-scale surveys of MNEs are often flawed because they simply cannot include and accurately measure such a broad and complex array of factors. This is the driving factor behind our decision to use experiments, and to focus on predicting a manager's preference for a particular mode, rather than trying to predict an actual event. Nevertheless, this approach is sufficiently novel with the IB literature that we draw upon a diagram known as Coleman's Boat (Coleman, 1994) to illustrate our approach.

Ultimately our main variable of interest - distance - is often conceptualized at the national level, and our main criterion variable - a firm's actual entry mode - is specific to a particular company-country combination; and yet many of the mediating factors that link the two issues, such as perceptions of risk, are ultimately individual-level constructs. Coleman's Boat is a convenient diagram to break down such complex multi-level situations. Figure 1, adapted from Dow (2017) illustrates the distance - entry mode choice relationship.

Insert Figure 1 about here

The basic idea of a Coleman's Boat is that the top half of the diagram reflects issues at the macro level (i.e. the level of the firm and/or country); whereas the lower half of the diagram reflects issues at the level of the individual. The first part of the model (A to B) is how national level differences affect an individual's perceptions of a foreign country. This is an issue that has been addressed by authors such as Håkanson and Ambos (2010) and in our analyses we test it in order to confirm the validity of our measures of perceived distance. However, we want to emphasize that this is not the main focus of our paper, and we note that 
other factors such as personal experiences and potential biases in formation of our perceptions (e.g. Baack et al., 2015) may play a role here as well. The second part of the model (B to C) is how an individual's perception of the distance of a country influences their preferences for a particular entry mode into that country. This is the main focus of our paper. Note here that again we are not arguing that the perception of distance is the only antecedent of a person's preference for a particular alternative. As discussed earlier, other issues may also play a role. The third part of the model ( $\mathrm{C}$ to $\mathrm{D})$ is how an individual manager's preference for a particular entry mode influences the actual course of action that the firm takes. Again, we are not arguing that one individual's preference is the only determinant of what a firm does, but rather we argue that if the individual is part of the top management team, then their preferences are likely to play an important role in the final course of action taken. Other factors such as the preferences of other key stakeholders in the firm undoubtedly intervene, and there might be constraints emanating from outside the firm. This part of the model is one that we want to acknowledge; and note that is common to virtually all management research that seeks to explain firm choices, but we also want to make clear that it is not the focus of this study.

The challenge is that the preceding issues, when combined, represent a chain of arguments so complex that we contend that no single empirical investigation could adequately address them all. However, breaking the problem down into logical components along the lines illustrated in Figure 1 allows each stage to be more effectively investigated. In this instance our main contribution is to investigate the bottom of the boat - i.e. the B to C leg of the model. We don't deny that there are other aspects, but we also cannot resolve all of them within the confines of one paper. In addition to that, one of the main advantages of an experiment is that through randomization of the respondents, and careful manipulation of the scenarios, within each stage we can also hold the other factors constant. This allows for a 
cleaner test of the one or two specific issues at hand. The use of an experiment also allows us to employ more sophisticated instruments for measuring the complex constructs. In the following sections, we outline the sample, experimental design, main treatment, and measurement of the dependent and independent variables.

\section{Sample}

The participants for this experiment were a randomly selected sample of experienced, Australian-based managers drawn from a database of alumni for management education programs (both degree granting and executive short-courses) offered by a leading university in Australia. Respondents were solicited in two waves of 600 and 400 people, respectively, in November 2010 and February 2011. To encourage participation, the respondents for each wave of data collection were entered into raffles for an iPad. The first wave yielded 129 complete surveys for a net response rate of 21.5 percent, while the second wave yielded 71 complete responses for a net response rate of 17.8 percent. The two waves of data collection were compared on seven respondent characteristics and no overall statistically significant difference was found (Manova: $\mathrm{df}=7, \mathrm{~F}=0.998, \mathrm{p}>0.05$ ). In total, 27 percent of the respondents were female, which is broadly comparable to the population of Australian managers in general-29.8 percent female as reported by ABS (2009). Overall, the respondents had an average age of 41.7 years and 19.4 years of work experience. Thirty three percent (33 percent) of respondents classified themselves as senior managers, 29 percent classified themselves as middle managers, and 34 percent classified themselves as professionals or consultants. Please refer to Table 1 for more details on the respondents.

Insert Table 1 about here 


\section{Experimental design}

In order to test the stated hypotheses, a $4 \times 2$ experimental design was employed and implemented using an on-line survey of the aforementioned sample ${ }^{6}$. Respondents were given a scenario in which they were asked to play the role of the most senior manager of a mediumsized Australian firm that is considering possible entry modes for a manufacturing investment in a foreign country. The respondents were then asked to consider a second, slightly altered scenario concerning the same host country. The following two sections describe the two main manipulations of the experiment in more detail.

\section{The host countries.}

The first dimension of the research design concerns the identification of the country in which the firm is intending to invest. The experiment includes four possible host countries (the U.S., the Netherlands, China, and Vietnam); however, each respondent was only asked to consider one of those four countries. The countries were selected to reflect two nations which are psychically near to Australia and two nations which are psychically far from Australia. In order to make this selection, 119 nations were rank-ordered in terms of their distance from Australia using a formative index based on five dimensions selected from Dow and Karunaratna’s (2006) psychic distance stimuli scales (differences in language, religion, industrial development, education, and political systems). Using this criterion, Vietnam (ranked $90^{\text {th }}$ most distant from Australia out of 119 countries) and China $\left(92^{\text {nd }}\right.$ from Australia) were selected as the psychically distant countries from Australia while the Netherlands ( $8^{\text {th }}$ most distant $)$ and the USA ( $4^{\text {th }}$ most distant $)$ were selected as the near countries. It should be noted that while respondents were only presented with one the four

\footnotetext{
${ }^{6}$ As noted earlier, this research is part of a larger study which includes Baack et al. (2015). Other treatments were applied to the same respondents; however, all but one of these additional treatments (Step 5) were administered after Step 11 as described in Appendix.
} 
host countries, the final analyses are based on the respondents' actual perceptions of how

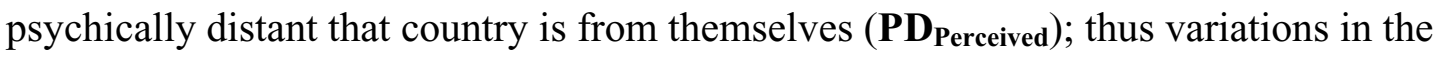
individual respondent's own experiences and biases are taken into account in the analyses. The high vs low threat of opportunism scenarios.

The second dimension of the research design concerns the potential for opportunistic behaviour by the local partner with respect to the proposed foreign investment. In order to manipulate this issue, each respondent was given two different scenarios: one in which the respondents were asked to select an entry mode in a situation where the threat of opportunism is relatively high and the other in which the threat of opportunism is relatively low. This distinction between high and low threat of opportunism was achieved by varying three aspects of the scenario descriptions. First, in the high opportunism scenario, the nature of the firm's proprietary knowledge was described as: sufficiently tacit and hard to communicate that it cannot be effectively patented. In contrast, in the low opportunism scenario, the firm's proprietary knowledge was described as a patented aspect of the product design. This dimension reflects Hennart's argument (1991: 486) that 'parents which transfer large amounts of tacit or poorly protected proprietary know-how to their subsidiaries will find that the pricing and the enforcement of licensing contracts with joint venture partners are fraught with difficulties.' Second, in addition to the patented product design, the low opportunism scenario is based on a firm-specific advantage attributable to superior manufacturing scale in a key component. Here we argue that the basis of the advantage (i.e. scale) is an attribute, which can be more objectively measured and thus monitored. This limits opportunism. Third, in the high opportunism scenario, the firm's main advantage is manifest in terms of a higher quality product - a multidimensional attribute which is arguably more difficult to measure (Agarwal and Ramaswami, 1992); whereas, for the low opportunism scenario, the firm's 
main advantage is manifest in terms of a substantial cost advantage — an attribute which is more amenable to quantification, measurement, and thus, monitoring.

Both the high and low opportunism scenarios were given to all respondents; however, the order in which they were introduced was varied randomly and controlled for in the analyses. For the purposes of our analyses, this manipulation is represented by a binary dummy variable labelled Opportunism.

Structure of the survey.

In terms of the structure and order in which participants were asked to complete the various tasks, the respondents were initially requested to assess their perceptions of the psychic distance of nine countries. The participants were then provided with a one-page business scenario which put them in the position of a senior manager of a medium-sized Australian manufacturing firm considering the possible entry mode choices for the establishment of a manufacturing facility in a specific country. At this same stage (i.e. embedded in the scenario), each participant was assigned to one of the four host country conditions and remained with that condition for the duration of the experiment. The respondent was also assigned to one of two conditions where either the high opportunism scenario would precede the low opportunism scenario or vice versa. Following the reading of the first scenario (high or low opportunism), the respondent assessed the degree of business risk they associated with that scenario and indicated their preferred entry mode into the market. The respondent was then presented the alternative scenario (in terms of high or low opportunism) and asked to repeat their assessments of the business risk and their preferred entry mode. See Appendix I for a detailed summary of these steps. 


\section{Dependent variables:}

Perceptions of business risk.

The first dependent variable in this study relates to hypotheses $\mathrm{H} 1 \mathrm{a}, \mathrm{H} 2 \mathrm{a}$ and $\mathrm{H} 3 \mathrm{a}$ and is the manager's perceptions of business risk for the given scenario. These perceptions were measured using a three item, 7-point scale instrument developed by Forlani, Parthasarathy, and Keaveney (2008) with one of the items reverse-coded (Appendix II). After testing for scale reliability and individual factor loadings using confirmatory factor analysis, the mean of the three items was employed as a single factor to measure the overall business risk (Risk). Given the process used to create the resultant factor, the scale was sufficiently linear and continuous in nature that multiple regression was used for all the analyses presented. While a more specific measure of risk may have been used, the use of an established scale was deemed more appropriate for this initial exploration of our hypotheses. To restate, as risk was not the focus of the study, more novel, less-established scales were deemed not appropriate. Preferred Entry Mode.

The second dependent variable relates to hypotheses $\mathrm{H} 1 \mathrm{~b}, \mathrm{H} 2 \mathrm{~b}$ and $\mathrm{H} 3 \mathrm{~b}$, and reflects the manager's preferred entry mode for the given scenario. The instrument is similar in structure to those used by Gatignon and Anderson (1988), and Delios and Henisz (2000); and includes a spectrum of four possible entry modes presented in decreasing order of equity control from the perspective of the survey respondent: a wholly-owned subsidiary, a majority share in a joint venture, a 50/50 joint venture, and a minority share in a joint venture. The resulting variable (Mode) was coded so that a value of 4 represents a wholly-owned subsidiary and a value of one represents a minority share in a joint venture. For this dependent variable, ordinal logistic regression was employed as the primary method of analysis but supplementary analyses were also performed by collapsing the three joint venture alternatives together and testing a binary variable (joint venture vs. wholly-owned subsidiary) using 
logistic regression (Arregle, Hebert, and Beamish, 2006; Brouthers and Brouthers, 2003;

Dikova and van Witteloostuijn, 2007).

\section{Independent variables:}

Perceptions of psychic distance.

Over the past 15 years a wide range of commentaries and research have emphasized the need for greater sophistication in the measurement of psychic distance and, in particular, a shift to measuring actual managerial perceptions of distance at the level of the individual (e.g. Child et al., 2002; Evans and Mavondo, 2002; Håkanson and Ambos, 2010; Sousa and Bradley, 2006; Tung and Verbeke, 2010). In response to this call, individual-level perceptions of psychic distance were measured in this study using best-worst scaling (BWS).

BWS, a technique borrowed from the field of choice modelling, is an efficient method for determining the strength of customer preferences amongst multiple discreet alternatives (Marley and Louviere, 2005) and has recently been validated with respect to the measurement of psychic distance by Dow (2009) and Baack et al. (2015). In this study, respondents were asked to compare the psychic distance from themselves for nine different countries. This set of nine includes the four host countries under investigation plus five benchmark countries (Brazil, Ecuador, India, Japan, and Mexico). The selection process for the benchmark countries broadly mirrors the section process for the host countries explained earlier. The benchmark countries were selected from a pool of 119 countries using the Dow and Karunaratna (2006) scales in order to provide a reasonable spread from very proximate countries (e.g. the UK) to very distant countries (e.g. Ecuador). As is the case in traditional BWS, each respondent was presented multiple times with subsets of the overall population of alternatives. In this instance, each respondent was presented with 12 rounds of three countries. For each three-country set, the respondent was asked to pick the country nearest to 
you in terms of psychic distance and the country furthest from you in terms of psychic

distance. The choice of 12 iterations allows for each country and country pair to be presented an equal number of times. To score these responses, each time a country is ranked as the nearest in its group of three, one point is subtracted, and each time it is ranked as the furthest one point is deducted. The net result is a scale ( $\left.\mathbf{P D}_{\text {Perceived }}\right)$ that ranges from -4 to +4 with a positive score indicating a country that is psychically distant from Australia, and a negative indicating a country that is psychically proximate to Australia (when compared to the average of the 9 benchmark countries). Before beginning this process, each respondent was primed with a definition of psychic distance that included the traditional Uppsala definition: 'the sum of factors preventing or disturbing the flow of information between firm and market.

Examples of such factors are differences in language, culture, political systems, level of education, level of industrial development, etc.' (Johanson and Wieidersheim-Paul, 1975: 308) plus supplementary comments reflecting more recent views and interpretations of the construct.

\section{Supplementary variables.}

In addition to the variables discussed above, two sets of supplementary variables were also collected for this experiment. The first set of supplementary variables concerns the antecedents of perceptions of psychic distance. In particular, a formative index was created using the five main dimensions from Dow and Karunaratna's (2006) set of psychic distance stimuli-differences in language, religion, industrial development, education, and degree of democracy. Bilateral data for these five dimensions were downloaded for 120 countries

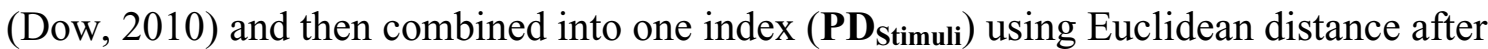
normalising for differences in variance across the scales. In addition to this index of psychic distance stimuli, three scales measuring the survey respondent's personal experiences with the host country were administered. These scales measured the number of times the 


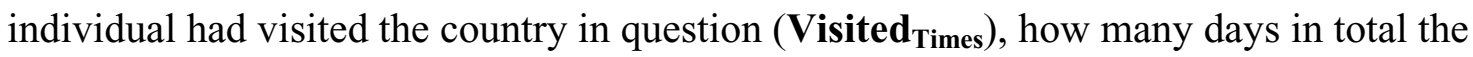
person had visited that country (Visited Days $_{\text {), }}$, and whether the individual had lived in the country for an extended period (Lived). This later variable was measured in years. The survey had originally included a variable to account for migration from the nominated country to Australia; however, the incidence of this was so low that it was combined with the Lived variable and the maximum value was imputed in such instances. All three local experience variables were subjected to a natural logarithm transformation to reduce skew. All four of these variables ( $\mathbf{P D}_{\text {Stimuli }}$ and the three experience variables) were used to verify the

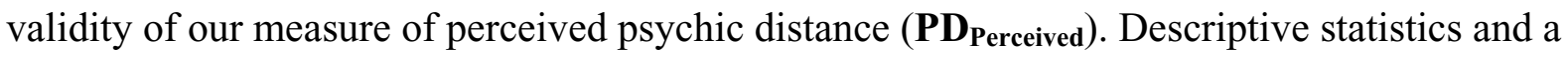
correlation matrix for all of the preceding variables can be found in Table 2.

The second set of supplementary variables were individual-level survey respondent characteristics and were used to confirm the nature of the survey population. These included the age, gender, education, and aspects of the respondent's work experience and, as already mentioned, are summarised in Table 2.

Insert Table 2 about here

\section{RESULTS}

\section{Preliminary analyses}

In preparation for the formal testing of the hypotheses, two preliminary sets of analyses were conducted. First, the three indicators of perception of risk were subjected to confirmatory factor analysis. As was the case with the original application of these scales (Forlani et al., 2008), all three items load very strongly $(>0.900)$ on to one common factor and the overall 
Cronbach Alpha is quite high at 0.926 (Appendix II). As a result, our measure of perceptions of risk (Risk) is within acceptable parameters.

The second preliminary analysis was a regression of the psychic distance stimuli index $\left(\mathbf{P D}_{\text {Stimuli }}\right)$ and the three measures of local experience (Visit Times, $_{\text {Visit }}$ Days $_{\text {and Lived) on to }}$

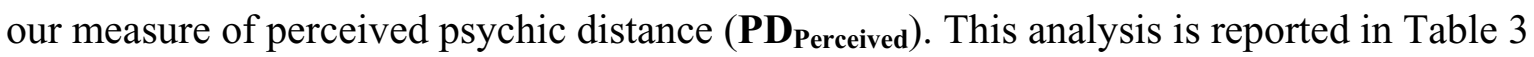
(Models 1 and 2) and the four antecedents combined yield an adjusted $\mathrm{R}^{2}$ of $0.562(\mathrm{~F}=$ $64.87, \mathrm{p}<0.001)$. The only non-significant variable is the measure of the number of times the respondent has visited that country. Subsequent analyses (available from the authors on request) indicate that this non-significance appears to be due to mild collinearity with the other visited variable. Thus, there is strong evidence that our measure of perceived psychic distance ( $\mathbf{P D}_{\text {Preceived }}$ ) is a valid instrument. It should also be noted here that this is an interesting illustration of the degree to which individual perceptions of distance (PDPerceived) can vary from national-level factors (i.e. PD $_{\text {Stimuli) }}$ and to what extent a relatively small number of individual-level factors can explain that gap.

Insert Table 3 about here

\section{Predicting perceptions of business risk}

From here, we now proceed to a formal testing of the hypotheses. The first stage is a pair of multiple regressions predicting the manager's perceptions of business risk. Model 3 in Table 4 is statistically significant $(\mathrm{F}=35.4, \mathrm{p}<0.001)$ and shows that perceptions of psychic distance significantly increase perceptions of risk $(t=7.96, p<0.001)$, confirming hypothesis H1a. It also demonstrates that the threat of opportunism significantly increases perceptions of risk $(\mathrm{t}=2.72, \mathrm{p}<0.01)$, confirming hypothesis H2a. In Model 4, these two variables are retained and a moderating variable combining them $\left(\mathbf{P D}_{\text {Perceived }} *\right.$ Opportunism) is 
introduced. In order to minimize collinearity, both variables were standardized before being combined into a moderating variable (Aiken and West, 1991). Model 4 indicates that the threat of opportunism does not appear to moderate the impact of psychic distance on perceptions of risk $(\mathrm{t}=0.28, \mathrm{p}>0.05)$ and thus, $\mathrm{H} 3 \mathrm{a}$ is not supported.

Insert Table 4 about here

\section{Predicting entry mode preferences}

Next we move on to the series of ordinal logistic regressions predicting entry mode preferences (Table 5) in order to test the remaining hypotheses (H1b, H2b and $\mathrm{H} 3 \mathrm{~b})$. Ordinal logistic regression is used here because this second dependent variable - mode preference represents an ordinal but not continuous, nor necessarily an equal interval ranking of alternatives. Model 5 in Table 5 is statistically significant $($ Chi Squared $=59.08, \mathrm{p}<0.001)$ and shows that perceptions of psychic distance significantly increase the preference for lower control modes - i.e. joint ventures with low foreign partner equity $($ Wald $=42.75, \mathrm{p}<0.001)$. This confirms hypothesis H1b. Similarly, Model 5 also demonstrates that the threat of opportunism significantly increases the preference for higher control modes (Wald $=16.26, \mathrm{p}$ $<0.001$ ), confirming hypothesis H2b. However, in Model 6, when the two are combined into a moderating variable, the moderating effect is once again non-significant (Wald $=0.01, p>$ 0.05). Thus, hypothesis H3b is not supported.

Insert Table 5 about here 
In brief summary, the results of the two preceding sets of analyses (i.e. Models 3 and 4 in Table 7, and Models 5 and 6 in Table 8) confirm that psychic distance appears to increase perceptions of risk and a preference for lower equity involvement by the foreign partner; thus confirming the new internalization perspective. However, the results also appear to confirm the role of the threat of opportunism in increasing perceptions of risk and a preference for wholly-owned subsidiaries. But, in both cases, psychic distance does not appear to play any significant role in magnifying the impact of the threat of opportunism, despite numerous commentators (e.g. Gatignon and Anderson, 1988; Zhao et al., 2004) classifying it as such.

\section{Additional analyses}

For our first supplementary analyses, we have rerun Models 3 thorough 6 using the index of psychic distance stimuli, $\mathbf{P D}_{\text {Stimuli, }}$ in place of perceived distance, $\mathbf{P} \mathbf{D}_{\text {Percieved }}$. These analyses are available upon request from the authors, but the results are essentially the same. Both the sign and statistical significance of all of the coefficients are the same regardless of whether one uses perceived distance or an index of psychic distance stimuli; however the standardized loading of the distance metric and the overall explained variance are higher when perceived distance is employed.

For the second supplementary analysis, we turn to Models 7 and 8 in Table 5. While it is not explicitly a hypothesis in this paper, the combination of H1a (psychic distance increases perceptions of risk) and $\mathrm{H} 1 \mathrm{~b}$ (psychic distance strengthens the preference for joint ventures) implies that at least in the low threat of opportunism scenario, one should expect perceptions of risk to be positively related to a preference for lower equity control. The difficulty is that the combination of $\mathrm{H} 2 \mathrm{a}$ (the threat of opportunism increasing perceptions of risk) and $\mathrm{H} 2 \mathrm{~b}$ (the threat of opportunism increasing preference for wholly-owned subsidiaries) implies that in the high threat of opportunism scenario, higher risk should be related to a preference for 
higher equity control. In effect, if you do not control for the potential for opportunism, the relationship between perceptions of risk and mode preference can go either way. Models 7 and 8 in Table 5 are introduced in order to explore this issue further. In theory, a moderated regression should be able to resolve the preceding dilemma. Unfortunately, while both Models 7 and 8 are statistically significant, in both cases it is entirely due to the direct effect of the threat of opportunism. Both a direct relationship between risk and mode preference, and a relationship moderated by the threat of opportunism are non-significant. These perplexing results and the other implications of our results are discussed further in the next section.

In a third and final set of supplementary analyses, we explore alternative specifications of our dependent variable - entry mode preference. Specifically, given the ordinal nature of this variable, the analyses relating to Models 5 through 8 have been repeated with a binary dependent variable (i.e. joint venture versus wholly-owned subsidiary) and binary logistic regression. This mirrors the approach taken by numerous other researchers (e.g. Arregle, Hebert, and Beamish, 2006; Brouthers, 2002; Sanchez-Peinado, Pla-Barber, and Hebert, 2007) and essentially the same findings are confirmed ${ }^{7}$.

\section{DISCUSSION AND CONCLUSIONS}

Overall, the empirical results of this study present a fairly strong and consistent pattern. All four of the direct effect hypotheses are supported; however, none of the moderating hypotheses are supported. At a theoretical level this has major implications for the role of psychic distance in the entry mode decision. It implies that psychic distance plays a major role in entry mode choice decisions by increasing the need to access complementary local assets, but it does not appear to play any significant role in magnifying the concerns about

\footnotetext{
${ }^{7}$ These analyses are available on request from the lead author.
} 
opportunism by the EJV partner. This is not to say that opportunism does not exist. Quite to the contrary, the threat of opportunism seems to play a significant role in entry mode choices as evidenced by the support for $\mathrm{H} 2 \mathrm{~b}$, but psychic distance does not seem to magnify those concerns. As a result, the major contribution of this paper at a theoretical level is a clarification of the role that psychic distance plays in entry mode choice. The psychic distance between the MNE and the host market stakeholders does appear to be a major source of uncertainty, influencing both perceptions of risk and a preference for lower equity modes; thus creating a need for complementary local assets. However, the psychic distance between the MNE and its local partner(s) in the host market does not appear to be playing any significant role magnifying concerns of opportunism. One possible explanation for this null result with respect to the moderating relationship is that in distant markets, firms are possibly compensating for their diminished ability in monitoring their EJV partners through other mechanisms; thus negating the need for higher ownership. This is a perspective that was recently highlighted by Hödl et al. (2012).

An implication of these results is that, despite our original expectations, the weak but positive relationship between distance and a preference for joint ventures reported by Zhao et al. (2004) and others does not appear to be the result of the counter opposing effects of distance cancelling each other out. Instead, the weak effects appear be more a function of limitations of the dominant methodological approach of the field. Large sample size field surveys rely heavily on secondary data and/or relatively simple proxy variables. This is particularly true with respect to the measurement of psychic distance. Approaches relying exclusively on secondary data are also constrained in terms of controlling for other factors.

This leads us to the second major contribution of this study - to our knowledge this paper, along with the affiliated article (Baack et al., 2015), is the first entry mode study to employ an experimental approach. This is significant for several reasons. First of all, as mentioned 
above, the experimental approach allowed us to employ more direct and sophisticated instruments to measure some of the key constructs, such as psychic distance and the threat of opportunism. In the case of psychic distance, numerous commentators (Brouthers and Brouthers, 2001; Shenkar, 2001; Tung and Verbeke, 2010) have argued that researchers should measure individual-level managerial perceptions of distance but unfortunately, accessing such perceptions a priori can be problematic (Dow and Karunaratna, 2006). The experimental approach resolves this problem and, as such, we believe this is the first instance of a study using a priori perceptions of psychic distance. In terms of measuring the threat of opportunism, the experimental approach again offers substantial benefits in allowing a far richer characterisation of the construct than the more commonly used proxy - the R\&D intensity of the firm or industry (Zhao et al., 2004).

Another aspect of our methodological approach which may explain why we have found such strong support for the accessing tacit local knowledge hypothesis, when prior research has, at best, found only weak support (e.g. Zhao et al., 2004), may be the nature of the second dependent variable used in this study. We are measuring preferences for a particular entry mode rather the actual entry mode used by a firm. This distinction is critical, especially when one is dealing with joint ventures which require the cooperation of a third party-an appropriate local partner. Circumstances may dictate that a joint venture is a superior and preferred solution to the problem, but if an appropriate local partner is not available (and on the right terms), then the desired mode may not be possible. This introduces a substantial amount of idiosyncratic variance into the equation when one is trying to predict the actual entry mode.

In addition to allowing the inclusion of more sophisticated instruments, the experimental approach also allows more flexibility in controlling for other factors, in constructing tests to disentangle moderating relationships, and in demonstrating causality (Leung et al., 2005). 
Indeed, it is these beneficial aspects that have allowed us to more effectively discriminate between the roles of psychic distance in entry mode choice.

A final benefit of the experimental approach is that it allowed us to directly measure a key mediating variable in the TCE explanation of entry mode choice - the manager's perception of business risk. In all of the large sample-size surveys that populate the existing literature, we would argue that this mediating variable was neglected because it was simply not feasible - due to the post hoc nature of the research. In this respect, this represents one of the strengths of this study, but it is also the source of one of the unexpected and slightly baffling empirical results. When one includes a previously unmeasured mediating variable in a relationship (e.g. A causes $\mathrm{B}$, and B causes $\mathrm{C}$ ), the a priori expectation is that the mediating variable (B) will be a superior predictor of the ultimate dependent variable (C) than the initial independent variable (A). The reason for this expectation is that in the full mediating relationship, the entire impact of $\mathrm{A}$ on $\mathrm{C}$ should be through $\mathrm{B}$, but there may also be other factors influencing B which a simple regression of A on C would not capture. However, as we observed with Models 7 and 8 in Table 5, the mediating variable (perceptions of business risk) is in fact a substantially weaker predictor of entry mode preference than the initial independent variable (perceptions of psychic distance). In fact, the explained variance drops to roughly one third of the original value (pseudo $\mathrm{R}^{2}=0.049$ in Model 8 versus 0.150 in Model 6).

There are a variety of potential explanations for this unexpected result. One possibility is that the measurement of the mediating variable is flawed. In particular, while our measure of risk has been used in prior research (Forlani et al., 2008) and empirically seems to have a high reliability, it may in fact be too general a measure of risk. Indeed, this issue of exploring and/or developing more fine-grained measures of perceived of risk is at the top of our list for further research. However, we would note that our risk measure performed adequately as a dependent variable in Models 3 and 4. It is only in Models 7 and 8 as an independent variable 
and moderator that it consistently yield null results. A second potential explanation, and one we feel is both more plausible and represents a cautionary note for such research, is that some respondents may be implicitly factoring in their preferred entry mode into their considerations of the business risk. In effect, we may have an endogeneity problem. What we ideally want to measure is the manager's perceptions of risk - independent of any consideration of entry mode. However, there are only very limited means by which we can stop respondents from implicitly factoring their preferred entry mode choice into their assessment of the situation. Although this may be seen as a limitation of our research, there is opportunity for future researchers to look at this relationship with other measures of business risk.

Another limitation of this study is one that is inherent to a great deal of experimental research. While we have taken every precaution to ensure that our sample of respondents is representative of the types of managers who may make such an entry mode decision, it is inescapable that this is an artificial decision, and in particular the decision maker does not have any real assets at risk. As a result, the managers may not behave in the same manner as when there are real assets at risk. However, we argue here that if there is any deviation in behaviour due to this limitation, it will probably be towards understating the perceptions of risk and preferences for risk adverse alternatives. Given that there are no actual assets at risk, the respondents are likely to take greater risks. As such, the impact of both the threat of opportunism and the need for tacit local knowledge may be understated in this research.

A third limitation of this research are the issues raised by Benito et al. (2009). Foreign operation modes are inherently messy - firms often employ more than one mode of operation at a time, even within the same host country; and mode choices are not static - firms often adapt and change modes over time. Obviously within the confines of an experiment-based investigation we have had to make some simplifying assumptions and constrain our focus to a 
single decision at one point in time, and to a limited set of environmental factors. However, we argue that while our approach is a simplification of reality, it can assist in adding insight into why firms often employ different modes at different times; and even different modes in parallel. Specifically our key moderating factor - the threat of opportunism may vary over time, and may vary across different functions. Thus, for example, a firm may believe that there is a high threat of opportunism in the manufacturing of the product, and thus choose to wholly-own the local manufacturing facility, but believe that the threat of opportunism is low in the sales function, and thus prefer a joint venture in that area to access critical local knowledge and relationships.

A fourth limitation of this research is that the knowledge-based view of the firm heavily overlaps with the TCE perspective when applied to international entry mode decisions. While each theoretical perspective focuses on different mechanisms and motives, they largely make parallel predictions about the relationship between psychic distance, tacit knowledge, and entry mode. As a result, while we have framed our predictions within the TCE perspective, the observed results with respect to $\mathrm{H} 1$ and $\mathrm{H} 2$ may reflect a combination of both theories. Nevertheless, the dilemma of contradictory predictions remains and we would argue that the moderating role of the threat of opportunism is still the most effective approach for discriminating between them.

A final limitation of this research concerns the use of a single home country-Australia. Such an approach not only exposes our results to particular home country biases, but the use of a single home country also limits the ability to discriminate between true distance effects and effects related to host market characteristics. For example, there may be a high correlation between the psychic distance from Australia and the political risk of a country such as Vietnam. While our measurement of individual level perceptions of psychic distance 
does allow us to partially limit that problem, replication of the study in a wider variety of home countries is highly advisable.

In terms of implications for practicing managers, it should be strongly stated that this is a descriptive model. Our research only demonstrates that managers believe that psychic distance increases uncertainty but that it does not increase their concerns about opportunism. It does not necessarily demonstrate that those views are correct. However, given that the existing body of research covers an exceptionally large number of entry mode decisions over several decades, it is reasonably likely that, in general, these managerial beliefs are reasonably accurate. As such, it is not unreasonable to suggest that, in the instance of capital investments in psychically distant markets, a joint venture, given appropriate safeguards concerning threat of opportunism, may be an appropriate vehicle for reducing the risk of the venture by providing access to critical complementary local assets.

In conclusion, we argue that this paper resolves a key contradiction in terms of the role that distance plays in entry mode choices and, through the use of an experiment research design, represents a step-change improvement in the measurement of several of the key underlying constructs.

\section{REFERENCES}

ABS. 2009. Women in Management by Occupation, ABS.

Agarwal S, Ramaswami SN. 1992. Choice of foreign market entry mode: impact of ownership, location and internalization factors. Journal of International Business Studies 23(1): 1-27.

Agarwal S. 1994. Socio-cultural distance and the choice of joint ventures: a contingency perspective. Journal of International Marketing 2(2): 63-80.

Ahsan M, Musteen M. 2011. Multinational enterprises' entry mode strategies and uncertainty: a review and extension. International Journal of Management Reviews 13: 376-392. 
Aiken LS, West SG. 1991. Multiple Regression: Testing and Interpreting Interactions. Sage Publications: Newbury Park, CA.

Ambos B, Håkanson L. 2014. The concept of distance in international management research. Journal of International Management, 20(1): 1-7.

Anderson E, Gatignon H. 1986. Modes of foreign entry: a transaction cost analysis and propositions. Journal of International Business Studies 17(3): 1-26.

Arregle JL, Hebert L, Beamish P. 2006. Mode of international entry: the advantages of multilevel methods. Management International Review 46(5): 597-618.

Baack DW, Dow D, Parente R, Bacon D. 2015. Confirmation bias in individual-level perceptions of distance: An experimental investigation. Journal of International Business Studies, 46(8): 938-59.

Benito GRG, Petersen B, Welch LS. 2009. Towards more realistic conceptualisations of foreign operation modes. Journal of International Business Studies, 40(9): 1455-70.

Benito, GRG, Petersen B, Welch LS. 2011. Mode combinations and international operations: theoretical issues and an empirical investigation. Management International Review, 51(6): 803-20.

Brouthers KD, Brouthers LE. 2001. Explaining the national cultural distance paradox. Journal of International Business Studies 32(1): 177-192.

Brouthers KD, Brouthers LE. 2003. Why service and manufacturing entry mode choices differ: the influence of transaction cost factors. Journal of Management Studies 40(5): 1179-1204.

Brouthers KD, Hennart JF. 2007. Boundaries of the firm: insights from international entry mode research. Journal of Management 33(3): 395-425.

Brouthers KD. 2002. Institutional, cultural and transaction cost influences on entry mode choice and performance. Journal of International Business Studies 33(2): 203-221.

Brouthers LE, Brouthers KD, Werner S. 2000. Perceived environmental uncertainty, entry mode choice and satisfaction with EC-MNC performance. British Journal of Management 11(3): 183-195.

Brouthers LE, Brouthers KD, Werner S. 2002. Industrial sector, perceived environmental uncertainty and entry mode strategy. Journal of Business Research 55(6): 495-507.

Buckley PJ, Devinney TM, Louviere JJ. 2007. Do managers behave the way theory suggests? A choice-theoretic examination of foreign direct investment location decisionmaking. Journal of International Business Studies 38(7): 1069-1094. 
Chang S-J, Rosenzweig PM. 2001. The choice of entry mode in sequential foreign direct investment. Strategic Management Journal 22(8): 747-776.

Child J, Ng SH, Wong C. 2002. Psychic distance and internationalization. International Studies of Management \& Organizations 32(1): 36-56.

Coleman JS. 1994. Foundations of Social Theory. Harvard University Press: boston, MA..

Cuypers IRP, Martin X. 2010. What makes and what does not make a real option? A study of equity shares in international joint ventures. Journal of International Business Studies 41: 47-69.

Cuypers IRP, Ertug G, Hennart JF. 2015. The effects of linguistic distance and lingua franca proficiency on the stake taken by acquirers in cross-border acquisitions. Journal of International Business Studies, 46(4): 429-42.

Delios A, Beamish P. 1999. Ownership strategy of Japanese firms: Transactional, institutional and experience influences. Strategic Management Journal, 20(10): 91533.

Delios A, Henisz WJ. 2000. Japanese firms' investment strategies in emerging economies. Academy of Management Journal 43(3): 305-323.

Demirbag M, Glaister KW, Tatoglu E. 2007. Institutional and transaction cost influences on MNE ownership strategies of their affiliates: evidence from an emerging market. Journal of World Business 42(4): 418-434.

Dikova D, van Witteloostuijn A. 2007. Foreign direct investment mode choice: entry and establishment modes in transition economies. Journal of International Business Studies 38(6): 1013-1033.

Dow D, Karunaratna A. 2006. Developing a multidimensional instrument to measure psychic distance stimuli. Journal of International Business Studies 37(5): 575-577.

Dow D, Larimo J. 2009. Challenging the conceptualization and measurement of distance and international experience in entry mode choice research. Journal of International Marketing 17(2): 74-98.

Dow D. 2009. Factors influencing perceptions of psychic distance. Paper presented at the Academy of International Business, San Diego.

Dow D. 2010. MBS: Dow—research website. http://www.mbs.edu/home/dow/research/ (14 June 2010).

Dow, D. 2017. Are We at a Turning Point for Distance Research in International Business Studies? In Progress in International Business Research - Distance in International 
Business: Concept, Cost and Value. Verbeke A, van Tulder R, Puck J (eds.), Emerald Group Publishing Limited: 47-68.

Erramilli MK, Rao CP. 1993. Service firms international entry mode choice: a modified transaction cost analysis approach. Journal of Marketing 57(3): 19-38.

Evans J, Mavondo FT. 2002. Psychic distance and organizational performance: an empirical examination of international retailing operations. Journal of International Business Studies 33(3): 515-532.

Forlani D, Parthasarathy M, Keaveney SM. 2008. Managerial risk perceptions of international entry mode strategies. International Marketing Review 25(3): 292-311.

Gatignon H, Anderson E. 1988. The multinational corporation's degree of control over foreign subsidiaries: an empirical test of a transaction cost explanation. Journal of Law, Economics and Organization 4(2): 305-336.

Gomes-Casseres B. 1990. Firm ownership preferences and host government restrictions: an integrated approach. Journal of International Business Studies 21(1): 1-22.

Håkanson L, Ambos B. 2010. The antecedents of psychic distance. Journal of International Management 16(3): 195-210.

Håkanson L, Ambos B, Schuster A, Leicht-Deobald U. 2016. The psychology of psychic distance: Antecedents of asymmetric perceptions. Journal of World Business, 51(2): 308-18.

Harzing AW. 2003. The Role of Culture in Entry Mode Studies: From Neglect to Myopia. In Advances in International Management. Cheng J, Hitt M (eds.), Elsevier / JAI: Amsterdam/New York.

Hennart JF. 1988. A transaction costs theory of equity joint ventures. Strategic Management Journal 9(4): 361-374.

Hennart JF. 1991. The transaction costs theory of joint ventures: an empirical study of japanese subsidiaries in the United States. Management Science 37(4): 483-497.

Hennart JF. 2009. Down with MNE-centric theories! Market entry and expansion as the bundling of MNE and local assets. Journal of International Business Studies, 40(9): 1432-54.

Hennart JF, Larimo J. 1998. The impact of culture on the strategy of multinational enterprises: does national origin affect ownership decisions? Journal of International Business Studies 29(3): 515-538.

Hennart JF, Zeng M. 2005. Structural determinants of joint venture performance. European Management Review, 2(2): 105-15. 
Hödl MK, Puck JF, Filatotchev I, Wolff H-G. 2012. The effect of ownership mode commitment and cultural distance on the extent of parent firm's strategic control over subsidiaries. Paper presented at the Academy of International Business, Washington, D.C.

Hofstede G. 1980. Cultural Consequences: International Differences in Work Related Values. Sage Publications: Beverly Hills, CA.

Johanson J, Vahlne J-E. 1977. The internationalization process of the firm-a model of knowledge development and increasing foreign commitments. Journal of International Business Studies 8(1): 23-32.

Johanson J, Wiedersheim-Paul F. 1975. The internationalization of the firm: four Swedish cases. Journal of Management Studies 12(October): 305-322.

Kim WC, Hwang P. 1992. Global strategy and multinationals' entry mode choice. Journal of International Business Studies 23(1): 29-53.

Kogut B, Singh H. 1988. The effect of national culture on the choice of entry mode. Journal of International Business Studies 19(3): 411-432.

Leung K, Bhagat RS, Buchan NR, Erez NR, Gibson CB. 2005. Culture and international business: recent advances and their implications for future research. Journal of International Business Studies 36(4): 357-378.

Lopez-Duarte C, Vidal-Suarez MM. 2010. External uncertainty and entry mode choice: cultural distance, political risk, and language diversity. International Business Review 19(6): 575-588.

Madhok A. 1998. The nature of multinational firm boundaries: transaction costs, firm capabilities and foreign market entry. International Business Review 7(3): 259-290.

Magnusson P, Baack DW, Zdravkovic S, Staub K, Amine L. 2008. Meta-analytsis of cultural differenecs: another slice at the apple. International Business Review 17(5): 520532.

Malhotra S, Sivakumar K, Zhu PC. 2011. Curvilinear relationship between cultural distance and equity participation: an empirical analysis of cross-border acquisitions. Journal of International Management 17(4): 316-332.

Marley AAJ, Louviere JJ. 2005. Some probabilistic models of best, worst, and best-worst choices. Journal of Mathematical Psychology 49(6): 464-480.

Meyer KE. 2001. Institutions, transaction costs, and entry mode choice in eastern Europe. Journal of International Business Studies 32(2): 357-367. 
Morschett D, Schramm-Klein H, Swoboda B. 2010. Decades of research on market entry modes: what do we really know about external antecedents of entry mode choice? Journal of International Management 16: 60-77.

Padmanabhan P, Cho KR. 1996. Ownership strategy for a foreign affiliate: an empirical investigation of Japanese firms. Management International Review 30(1): 45-65.

Root FR. 1987. Entry Strategies for International Markets. D. C. Heath: Lexington, MA.

Sanchez-Peinado E, Pla-Barber J, Hebert L. 2007. Strategic variables that influence entry mode choice in service firms. Journal of International Marketing 15(1): 67-91.

Shaver JM. 2013. Do we really need more entry mode studies? Journal of International Business Studies, 44(1): 23-27.

Shenkar O. 2001. Cultural distance revisited: towards a more rigorous conceptualization and measurement of cultural differences. Journal of International Business Studies 32(3): $519-536$.

Slangen A, van Tulder RJM. 2009. Cultural distance, political risk, or governance quality? Towards a more accurate conceptualization and measurement of external uncertainty in foreign entry mode research. International Business Review 18(3): 276-291.

Sousa CMP, Bradley F. 2006. Cultural distance and psychic distance: two peas in a pod? Journal of International Marketing 14(1): 49-70.

Tihanyi L, Griffith DA, Russell CJ. 2005. The effect of cultural distance on entry mode choice, international diversification, and MNE performance: a meta-analysis. Journal of International Business Studies 36(3): 270-283.

Tung RL, Verbeke A. 2010. Beyond Hofstede and GLOBE: improving the quality of crosscultural research. Journal of International Business Studies 41(8): 1259-1274.

Verbeke A, Kano L. 2012. An internalization theory rationale for MNE regional strategy. Multinational Business Review, 20(2): 135-52.

Verbeke A, Kano L. 2015. The new internalization theory and multinational enterprises from emerging economies: A business history perspective. Business History Review, 89(3): 415-45.

Williamson OE. 1975. Markets and Hierarchies. Free Press: New York.

Williamson OE. 1979. Transaction cost economics: The governance of contractual relationships. The Journal of Law and Economics, 69: 233-61.

Zaheer S, Schomaker MS, Nachum L. 2012. Distance without direction: restoring credibility to a much-loved construct. Journal of International Business Studies 43(1): 18-27. 
Zhao H, Luo Y, Suh T. 2004. Transaction cost determinants and ownership-based entry mode choice: a meta-analytic review. Journal of International Business Studies 35(6): 524-544.

This article is protected by copyright. All rights reserved. 


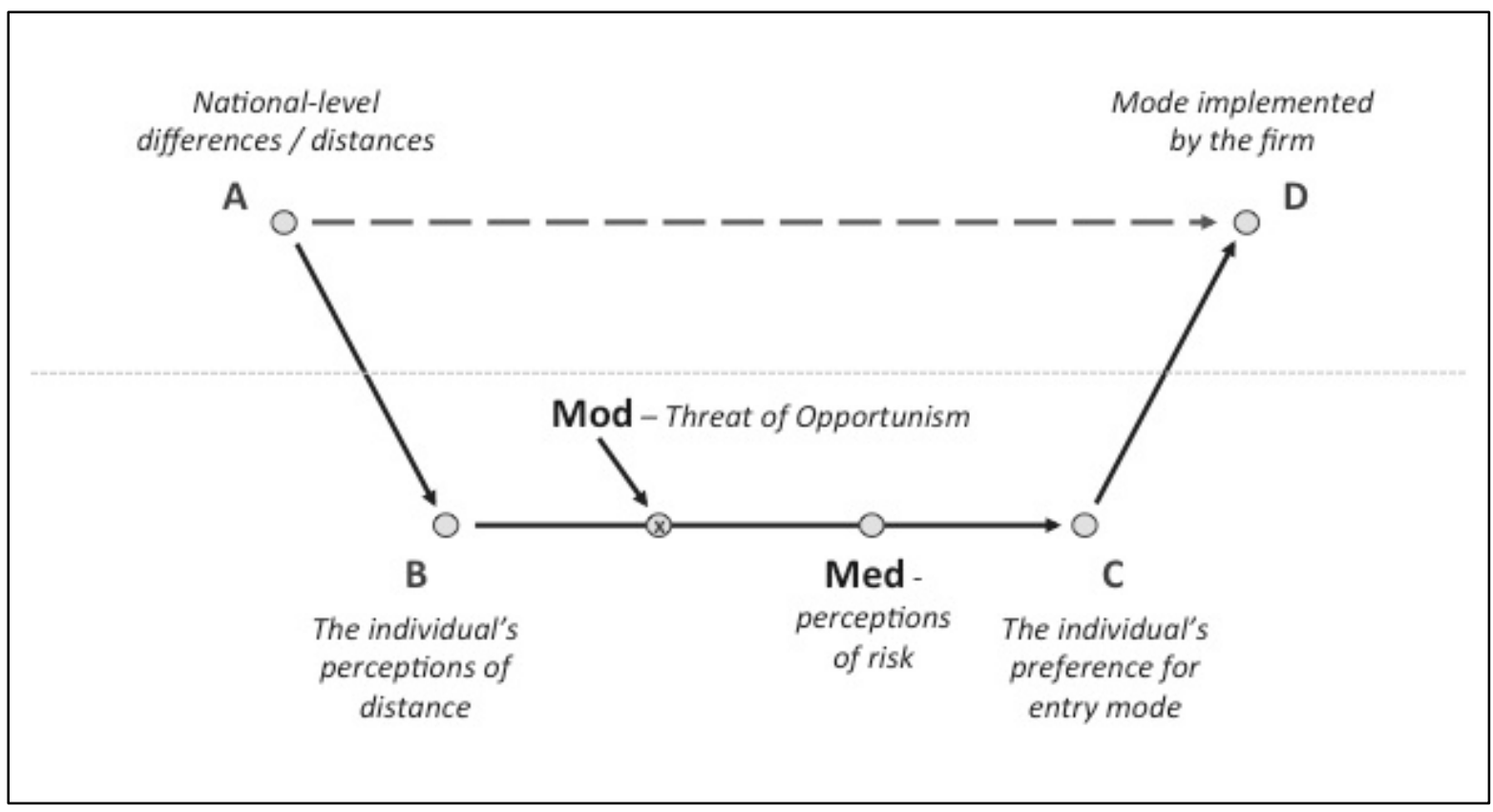

Figure 1. Coleman's Boat Adapted to the Distance - Entry Mode Issue

\section{Table 1}

Descriptive statistics for respondents $(n=200)$

\begin{tabular}{|c|c|c|c|c|c|}
\hline Variable & Description & Min & $\operatorname{Max}$ & Mean & $\begin{array}{l}\text { Standard } \\
\text { deviation }\end{array}$ \\
\hline Age & $\begin{array}{l}(6 \mathrm{pt} \text { scale, } 10 \mathrm{yr} \text { intervals: } \\
1 \text { represents } 20 \text { to } 29 \\
\text { years old })\end{array}$ & 1 & 6 & $\begin{array}{r}2.67 \\
\text { (equiv. to } \\
41.7 \mathrm{yrs} \text { ) }\end{array}$ & $\begin{array}{r}1.02 \\
\text { (equiv. to } \\
10.2 \text { yrs) }\end{array}$ \\
\hline Gender & $($ female $=1)$ & 0 & 1 & 0.27 & 0.45 \\
\hline $\begin{array}{l}\text { Work } \\
\text { experience }\end{array}$ & (years) & 2 & 5 & 19.41 & 9.60 \\
\hline $\begin{array}{l}\text { Size of } \\
\text { employer }\end{array}$ & (\# of employees) & 1 & 400,000 & 17,878 & 52,975 \\
\hline $\begin{array}{l}\text { Overseas } \\
\text { trips }\end{array}$ & $\begin{array}{l}\text { (total \# of trips to any } \\
\text { foreign country) }\end{array}$ & 0 & 250 & 24.14 & 32.06 \\
\hline Education & \multicolumn{5}{|c|}{95 percent have a Bachelor Degree or higher } \\
\hline Job title & \multicolumn{5}{|c|}{$\begin{array}{l}33 \text { percent classified themselves as senior managers, } 29 \text { percent as } \\
\text { middle managers and } 34 \text { percent as professionals/consultants }\end{array}$} \\
\hline
\end{tabular}




\section{Table 2}

Descriptive statistics and correlation matrix for key variables

\begin{tabular}{|c|c|c|c|c|c|c|c|c|c|c|c|c|c|c|}
\hline & Variable & Description & $\mathbf{n}$ & Min & Max & Mean & Std Dev & 1 & 2 & 3 & 4 & 5 & 6 & 7 \\
\hline 1 & $\mathrm{PD}_{\text {Stimuli }}$ & $\begin{array}{l}\text { Formative index of } 5 \text { main } \\
\text { dimension of distance } \\
\text { (Dow and Karunaratna, } \\
\text { 2006) }\end{array}$ & 200 & 0.26 & 7.31 & 3.58 & 3.37 & 1.00 & & & & & & \\
\hline 2 & Visited $_{\text {Times }}$ & $\begin{array}{l}\text { \# of personal visits to } \\
\text { host country }(\ln )^{t}\end{array}$ & 200 & 0 & 100 & 2.98 & 8.77 & $-0.32 * * *$ & 1.00 & & & & & \\
\hline 3 & Visited $_{\text {Days }}$ & $\begin{array}{l}\text { Cumulative time (days) } \\
\text { visiting host country (ln) }{ }^{t}\end{array}$ & 200 & 0 & 100 & 11.76 & 22.38 & $-0.16^{* *}$ & $0.56^{* * *}$ & 1.00 & & & & \\
\hline 4 & Lived & $\begin{array}{l}\text { Time (years) living in } \\
\text { host country }(\ln )^{t}\end{array}$ & 200 & 0 & 11 & 0.14 & 0.92 & -0.07 & 0.01 & 0.07 & 1.00 & & & \\
\hline 5 & $\mathrm{PD}_{\text {Perceived }}$ & $\begin{array}{l}\text { Perception of psychic } \\
\text { distance (BWS approach) }\end{array}$ & 200 & -4 & +4 & -0.40 & 2.50 & $0.69 * * *$ & $-0.42 * * *$ & $-0.40 * * *$ & $-0.17 * *$ & 1.00 & & \\
\hline 6 & Opportunism & $\begin{array}{l}\text { High vs low opportunism } \\
\text { scenario }(\text { high }=1)\end{array}$ & 400 & 0 & 1 & 0.50 & 0.50 & 0.00 & 0.00 & 0.00 & 0.00 & 0.00 & 1.00 & \\
\hline 7 & Risk & $\begin{array}{l}\text { Perceived risk } \\
\text { (mean of } 3 \text { items) }\end{array}$ & 400 & 1 & 7 & 3.95 & 1.43 & $0.52 * * *$ & $-0.24 * * *$ & -0.05 & -0.02 & $0.37 * * *$ & $0.13 *$ & 1.00 \\
\hline 8 & Mode & $\begin{array}{l}\text { Preferred entry mode } \\
\text { (Wholly-owned subsidiary } \\
=4 \text {, Minority JV = 1) }\end{array}$ & 400 & 1 & 4 & 2.88 & 0.89 & $-0.27 * * *$ & $0.14^{* *}$ & 0.07 & 0.09 & $-0.31 * * *$ & $0.20 * * *$ & -0.04 \\
\hline
\end{tabular}

$t$ - For the three experience variables, the minimums, maximums, means and standard deviations are reported before natural logarithm transformation; however the correlations and all subsequent analyses use the transformed versions of the variables.

$* \mathrm{p}<0.05 ; * \mathrm{p}<0.01 ; * * * \mathrm{p}<0.001$ 
Table 3

Regressions predicting perceptions of psychic distance ( $\left.\mathrm{PD}_{\text {Perceived }}\right)$

\begin{tabular}{lcc}
\hline \multicolumn{1}{c}{ Model } & \multicolumn{1}{c}{$\mathbf{1}$} & \multicolumn{1}{c}{$\mathbf{2}$} \\
\hline PD $_{\text {Stimuli }}$ & $0.686^{* * *}$ & $0.615^{* * *}$ \\
& $(13.26)$ & $(12.38)$ \\
Visited $_{\text {Times }}$ & & -0.079 \\
& & $(1.34)$ \\
Visited $_{\text {Days }}$ & & $-0.248^{* * *}$ \\
& & $(4.36)^{* *}$ \\
Lived & & $-0.111^{*}$ \\
\hline F & & $(2.35)$ \\
p & 175.9 & 64.87 \\
Adj R & $<0.001$ & $<0.001$ \\
\hline
\end{tabular}

Standardized coefficients, t-values in parentheses, two tailed tests $* \mathrm{p}<0.05 ; * * \mathrm{p}<0.01 ; * * * \mathrm{p}<0.001$

This article is protected by copyright. All rights reserved. 
Table 4

Regressions predicting perceptions of risk (Risk)

\begin{tabular}{lcc}
\hline \multicolumn{1}{c}{ Model } & \multicolumn{1}{c}{$\mathbf{3}$} & $\mathbf{4}$ \\
\hline PD $_{\text {Perceived }}$ & $\begin{array}{c}0.368^{* * *} \\
(7.96)\end{array}$ & $\begin{array}{l}0.368^{* * *} \\
(7.96)\end{array}$ \\
Opportunism & $0.126^{* *}$ & $0.126^{* *}$ \\
& $(2.72)$ & $(2.72)$ \\
PD $_{\text {Perceived }}$ * Opportunism & & -0.050 \\
\hline F & & $(0.28)$ \\
p & 35.4 & 24.0 \\
Adj $\mathbf{R}^{2}$ & $<0.001$ & $<0.001$ \\
\hline
\end{tabular}

Standardized coefficients, t-values in parentheses, two tailed tests

$* \mathrm{p}<0.05 ; * * \mathrm{p}<0.01 ; * * * \mathrm{p}<0.001$

This article is protected by copyright. All rights reserved. 


\section{Table 5}

Ordinal logistic regressions predicting entry mode preferences (Mode) ${ }^{t}$

\begin{tabular}{|c|c|c|c|c|}
\hline Model & 5 & 6 & 7 & 8 \\
\hline PD $D_{\text {Perceived }}$ & $\begin{array}{l}-0.258 * * * \\
(42.75)\end{array}$ & $\begin{array}{l}-0.258 * * * \\
(42.74)\end{array}$ & & \\
\hline Opportunism & $\begin{array}{l}0.767^{* * *} \\
(16.26)\end{array}$ & $\begin{array}{l}0.767^{* * *} \\
(16.24)\end{array}$ & $\begin{array}{l}0.737^{* * *} \\
(15.10)\end{array}$ & $\begin{array}{l}0.750 \text { *** } \\
(15.60)\end{array}$ \\
\hline PD $_{\text {Perceived }}$ * Opportunism & & $\begin{array}{l}0.007 \\
(0.01)\end{array}$ & & \\
\hline Risk & & & $\begin{array}{l}-0.067 \\
(1.05)\end{array}$ & $\begin{array}{r}-0.069 \\
(1.12)\end{array}$ \\
\hline Risk * Opportunism & & & & $\begin{array}{l}0.143 \\
(2.32)\end{array}$ \\
\hline Chi squared (df) & $\begin{array}{r}59.08 \\
(2)\end{array}$ & $\begin{array}{r}59.09 \\
(3)\end{array}$ & $\begin{array}{r}15.93 \\
(2)\end{array}$ & $\begin{array}{r}18.26 \\
(3)\end{array}$ \\
\hline $\mathbf{p}$ & $<0.001$ & $<0.001$ & $<0.001$ & $<0.001$ \\
\hline Nagelkerke Pseudo $\mathbf{R}^{2}$ & 0.150 & 0.150 & 0.043 & 0.049 \\
\hline
\end{tabular}

${ }^{t}$ - a positive value indicates a preference for higher levels of foreign parent control (e.g. a WOS). Unstandardized parameter coefficients, Wald statistics in parentheses, two tailed tests $\mathrm{p}<0.05 ; * * \mathrm{p}<0.01 ; * * * \mathrm{p}<0.001$

This article is protected by copyright. All rights reserved. 
Appendix I: The Experimental Design

\begin{tabular}{cl}
\hline Step & \multicolumn{1}{c}{ Activity } \\
\hline 1 & Introduction to the project (including confirming their consent to participate). \\
2 & $\begin{array}{l}\text { Measure the respondent's perception of psychic distance to nine countries (all four of the } \\
\text { countries in Step } 4 \text { plus five other countries intentionally selected to provide maximum } \\
\text { variance). }\end{array}$
\end{tabular}

\section{SCENARIO 1}

3 A one-page briefing on the first scenario. For half of the respondents, the high opportunism scenario is first; for the remainder, the low scenario is first. The scenarios are identical in all aspects other than the high vs low threat of opportunism.

4 Specify the host market to be considered with respect to the scenario. Each respondent is assigned one, and only one of four countries (USA, Netherlands, China or Vietnam).

5 Measure the respondent's familiarity with the specified country using four seven point Lickert type scales. [This scale is related to the 'second' experiment and is not directly relevant to this paper]

6 Measure respondent's perceptions of the business risk of the specified country in light of the first scenario using three seven point Lickert type scales.

7 Measure the respondent's preferred entry mode into the specified country in light of the first scenario based on a set of four alternatives (a wholly-owned subsidiary, a majority share in a joint venture, a 50/50 joint venture, or a minority share in a joint venture)

\section{SCENARIO 2}

8 A one-page briefing on the second scenario. For the respondents who have already seen the high opportunism scenario this will be the low opportunism scenario, and vice versa. The briefing confirms the identity of the same host country as in Step 3.

9 Measure respondent's perceptions of the business risk of the specified country in light of the second scenario using three seven point Lickert type scales.

10 Measure the respondent's preferred entry mode into the specified country in light of the second scenario based on a set of four alternatives (a wholly-owned subsidiary, a majority share in a joint venture, a 50/50 joint venture, or a minority share in a joint venture)

11 Measure a range of respondent demographics including age, gender work experience and international travel experience.

[Subsequent manipulations and instruments were included in the survey but relate to the experiments reported in Baack et al. (2015) and are not directly relevant to this paper.] 
Appendix II: Wording, Loadings and Reliability of Indicators of Perceived Risk

\section{Instructions}

In a similar fashion, we would like you to indicate your perceptions of the business risks of making such an investment in [name of country randomized]. With respect to the term business risk, we are referring to all potential factors which may hamper the long term financial viability of the investment.

For each scale below, please select the number which you feel best assesses the amount of RISK associated with establishing a manufacturing plant in this country as per the given scenario.

\begin{tabular}{|c|c|c|c|c|c|c|c|c|c|}
\hline \multirow[t]{2}{*}{ Var } & \multicolumn{2}{|c|}{ Description } & \multirow[b]{2}{*}{3} & \multirow[b]{2}{*}{4} & \multirow[b]{2}{*}{5} & \multirow[b]{2}{*}{6} & \multirow[b]{2}{*}{7} & \multirow[t]{2}{*}{ Loadings } & \multirow[t]{2}{*}{$\begin{array}{r}\text { Cronbach } \\
\text { Alpha } \\
\end{array}$} \\
\hline & 1 & 2 & & & & & & & \\
\hline R1 & High & & & & & & Low & 0.903 & \\
\hline $\mathrm{R} 2$ & Minimal & & & & & & Extreme & 0.945 & \\
\hline \multirow[t]{2}{*}{ R3 } & Not Risky & & & & & & Very Risky & 0.954 & \\
\hline & & & & & & & & & 0.926 \\
\hline
\end{tabular}




\section{University Library}

\section{- MINERVA \\ A gateway to Melbourne's research publications}

Minerva Access is the Institutional Repository of The University of Melbourne

Author/s:

Dow, D;Baack, DW;Parente, R

Title:

The Role of Psychic Distance in Entry Mode Decisions: Magnifying the Threat of Opportunism or Increasing the Need for Local Knowledge?

Date:

2020-05-01

\section{Citation:}

Dow, D., Baack, D. W. \& Parente, R. (2020). The Role of Psychic Distance in Entry Mode Decisions: Magnifying the Threat of Opportunism or Increasing the Need for Local Knowledge?. Global Strategy Journal, 10 (2), pp.309-334. https://doi.org/10.1002/gsj.1309.

Persistent Link:

http://hdl.handle.net/11343/283601 